\title{
1 In vitro activity of beauvericin against all developmental stages of 2 Sarcoptes scabiei
}

4 Charbel Al Khoury ${ }^{\text {a,b }}$, Nabil Nemer ${ }^{a, *}$, Georges Nemer ${ }^{c}$, Mazen Kurban ${ }^{\text {c,d }}$, Charlotte 5 Bernigaud $^{\text {b,e }}$, Katja Fischer ${ }^{\mathbf{f}}$, Jacques Guillot ${ }^{\text {b,** }}$

$7 \quad{ }^{a}$ Faculty of Agricultural and Food Sciences, Holy Spirit University of Kaslik, P.O. Box 446 8 Jounieh, Lebanon

$9{ }^{\boldsymbol{b}}$ Research group Dynamyc, EA7380, Université Paris-Est Créteil, Ecole nationale vétérinaire 10 d'Alfort, USC ANSES, 7 Avenue du Général de Gaulle, 94700 Maisons-Alfort, France

$11{ }^{c}$ Department of Biochemistry and Molecular Genetics, American University of Beirut, Riad El

12 Solh, Beirut, Lebanon

$13{ }^{d}$ Department of Dermatology, American University of Beirut, Beirut, Lebanon

$14{ }^{e}$ Department of Dermatology, Faculté de Médecine Paris-Est Créteil, AP-HP, Henri Mondor

15 hospital, 51 Avenue du Maréchal de Lattre de Tassigny, 94010 Créteil, France

$16{ }^{f}$ Scabies Laboratory, QIMR Berghofer Medical Research Institute, Infectious Diseases Program,

17 Brisbane, Australia

$18 *$ Corresponding author

19 Phone: +331 439670 62; E-mail: jacques.guillot@ vet-alfort.fr 


\section{Abstract}

22 Background: Scabies is a frequent cutaneous infection caused by the mite Sarcoptes scabiei in a

23 large number of mammals including humans. As the resistance of S. scabiei against several

24 chemical acaricides has been previously documented, the establishment of alternative and

25 effective control molecules is required.

26 Objectives: In this study, the potential acaricidal activity of beauvericin was assessed against

27 different life stages of S. scabiei var. suis and, in comparison with dimpylate and ivermectin, two

28 commercially available molecules used for the treatment of S. scabiei infection in animals and/or

29 humans.

30 Methods: In our in vitro model, developmental stages of S. scabiei have been placed in Petri

31 dishes filled with Columbia agar supplemented with pig serum and different concentrations of

32 the drugs. Moreover, the toxicity of beauvericin against cultured human fibroblast skin cells was

33 evaluated using an MTT proliferation assay

34 Results: Beauvericin showed higher activity against adults and eggs of S. scabiei when

35 compared to dimpylate and ivermectin. In addition, cell sensitivity assays demonstrated low

36 toxicity of beauvericin against primary human fibroblast skin cells.

37 Conclusion: These results revealed that the use of beauvericin is promising and might be 38 considered for the treatment of S. scabiei infection.

39 Keywords: Sarcoptes scabiei, scabies, beauvericin, mycotoxin, treatment 


\section{Introduction}

41 Scabies is a frequent cutaneous infection caused by the mite Sarcoptes scabiei in a large number

42 of mammals including human. ${ }^{1}$ Human scabies was recently recognized as a neglected tropical

43 disease by the WHO, due to its high global prevalence estimated to be around 100-200 million

44 cases a year, ${ }^{2}$ and high morbidity. ${ }^{3}$ Although primary infection with S. scabiei is limited to

45 severe itching and allergic rash, secondary infections with bacteria such as group A

46 streptococcus or Staphylococcus aureus could lead to severe acute infectious complications and

47 even death, ${ }^{4}$ hence the importance of early and efficient eradication of the mites. ${ }^{5}$ There is a

48 limited number of drugs that could be used for the treatment of scabies. Furthermore, the resistance to some of the drugs of $S$. scabiei is emerging, caused by re-infection or incorrect use

50 of acaricides, may lead to an excessive and random use of treatments posing threat to patient

51 health. ${ }^{6}$ Less susceptible populations of S. scabiei may emerge from the repeated exposure to a

52 single type of acaricide. The resistance development may involve a mutation to the target site of

53 the acaricide molecule or an up-regulation for genes encoding for detoxification enzymes (Van

54 Leewan et al., 2010). Therefore, the development of new acaricides with new mode of action

55 against $S$. scabiei is required.

56 Many secondary metabolites produced by fungi have been used in medicine and agriculture. ${ }^{7}$

57 The entomopathogenic fungus Beauveria bassiana is known to produce beauvericin, a secondary

58 metabolite belonging to the enniatin antibiotic family. ${ }^{8}$ This cyclic hexadepsipeptide was proven

59 to have many biological effects including insecticidal, antitumor, antibacterial, and antifungal

60 activity. ${ }^{9}$ Its mechanism of action is thought to be ionophore-induced apoptosis and DNA

61 fragmentation. ${ }^{7}$ Recently, there is an ongoing interest for cyclic depsipeptide as topically applied

62 medicines, treating per example, psoriasis, eczema and skin cancer (Cruz et al., 2009).

63 Accordingly, beauvericin could be considered as a potential new acaricide for the treatment of 
64 human and animal scabies. The objective of this study was to evaluate the in vitro efficacy of

65 beauvericin against the different life stages of S. scabiei. In addition, this study evaluated the 66 toxicity of beauvericin against cultured human fibroblast skin cells.

67 


\section{Materials and method}

\section{Ethics}

70 All animals were maintained in strict accordance with good animal practices as defined by the

71 French and European code of practice for the care and use of animals for scientific purposes

72 (approval No. 02515.01). The biopsies were obtained after a written consent form was secured

73 from each individual according to an approved protocol by the Institution Review Board (IRB) at

74 the American University of Beirut (Protocol Number: DER.MK.01). The experiments were

75 conducted in accordance with Good Clinical Practice and the ethical principles of the Helsinki

76 Declaration

\section{$77 \quad$ Sarcoptes mites}

78 Sarcoptes scabiei mites were collected from pigs maintained at CRBM (Centre de Recherche 79 Bio Médicale), Maisons-Alfort, France. Pigs were experimentally-infected as described by

80 Mounsey. ${ }^{10}$ Inoculation was done by directly introducing mite-infected skin crusts deep into the

81 ear canals of five-week-old female piglets. Glucocorticoid treatment was initiated in naive

82 piglets one week prior to inoculation and continued. For the present study, mites were collected

83 from the pigs in weeks 15 and 16. Crusts in the external ear canal were gently removed and

84 collected in a sterile Petri dish in the morning of the in vitro experiments. Mites crawled out of

85 the crusts in about half an hour. Then they were picked one by one with a needle and under a 86 dissecting stereomicroscope (Nikon@, SMZ645, Lisses, France).

\section{$87 \quad$ Molecules to be evaluated}

88 Beauvericin 97\% was purchased from Sigma-Aldrich. Dimpylate (diazinon) was purchased from 89 Huvepharma ${ }^{\mathrm{TM}}$ (Segre en Anjou, France) (Dimpygale ${ }^{\circledR}$, solution $100 \mathrm{mg} / \mathrm{ml}$ ). Ivermectin was 90 purchased from Boehringer-Ingelheim ${ }^{\mathrm{TM}}$ (Lyon, France) (Ivomec $\AA$, injectable solution $9110 \mathrm{mg} / \mathrm{ml})$. 


\section{In vitro efficacy tests on mites and eggs}

93 To assess the efficacy of drugs (including beauvericin) against S. scabiei motile stages

94 (larvae/nymphs and females), Petri dishes filled with Columbia agar supplemented with pig

95 serum have been used for bioassays. To prepare the medium, 42g of Columbia agar (Bio-Rad,

96 Marne-la-Coquette, France) were dissolved in 1L of distilled water. The solution was autoclaved

97 for $15 \mathrm{~min}$ at $121^{\circ} \mathrm{C}$ then cooled down in a water bath at $53^{\circ} \mathrm{C}$. Blood samples were obtained

98 from pigs maintained in CRBM. Tubes of blood were centrifuged at $4500 \mathrm{rpm}$ for $10 \mathrm{~min}$ at $4^{\circ} \mathrm{C}$.

99 The resulting supernatant was designated serum. For the preparation of each Petri dish, one ml of 100 serum was added to $18 \mathrm{ml}$ of Columbia agar medium at $53^{\circ} \mathrm{C}$. Drugs to be tested were 101 incorporated into the medium following the method described by Brimer ${ }^{11,12}$ with slight 102 modifications. The mycotoxin beauvericin and two acaricide drugs (dimpylate and ivermectin) were tested with different concentrations. The absence of drug concentration was considered as negative control. The required volumes of serum-supplemented Columbia agar and molecules were pipetted in a tube and quickly transferred to a $9 \mathrm{~cm}$ sterile plastic Petri dish under a flow cabinet. Petri dishes were kept under the flow cabinet until the agar is solidified, and stored upside down at $4^{\circ} \mathrm{C}$ until use. The efficacy of 3 different concentrations $0.5,5$, and $50 \mu \mathrm{M}$ was evaluated. Five females and five nymphs or larvae were inoculated in the middle of the plates and examined at 1, 2, 3, 4, 5, 6, 7, 8 and $24 \mathrm{~h}$ after inoculation for survival assessment of motile stages at room temperature. Mites were considered dead when no movement occurred under the

111 microscope during $5 \mathrm{~min}$ even after a gentle stimulation with a dissecting needle. After each 112 inspection, mites were moved again to the center of the plate using a dissecting needle to lower 113 chances of runaways.

114 To assess the efficacy of chemical products against S. scabiei eggs, 10 eggs were manually 115 isolated using a fine needle and placed in the middle of beauvericin, dimpylate, or ivermectin- 
116

117

118

119

supplemented agar plates under the dissecting stereomicroscope as described above. Petri dishes were maintained at $37^{\circ} \mathrm{C}$ in an incubator for 5 days to promote egg development. Newly hatched larvae were recorded and removed from the Petri dishes.

Five replications were performed in three biological replicates, making it a total of 150 motile stages and 150 eggs observed for each treatment.

\section{Primary fibroblast culture}

Human skin biopsies from healthy volunteer patients were delivered to the laboratory in culture medium (RPMI 1640: $450 \mathrm{ml}$, FBS: $50 \mathrm{ml}$, and penicillin-streptomycin solution x100: $1 \mathrm{ml}$ ). Each biopsy was transferred into a sterile Petri dish and rinsed with PBS to eliminate blood and debris. Two ml collagenase (Worthington ${ }^{\mathrm{TM}}$ ) were added to the medium before mincing the tissue with a scalpel. After incubation at $37^{\circ} \mathrm{C}$ for $1 \mathrm{~h}$, the digested tissue was transferred to a $15 \mathrm{ml}$ conical tube and the Petri dish was rinsed twice with $2 \mathrm{ml}$ of the medium and the liquid was collected in the same tube and span down at $200 \mathrm{~g}$ for $5 \mathrm{~min}$ at room temperature. The pellet was washed twice with $3 \mathrm{ml}$ of the medium to remove the collagenase, resuspended with $5 \mathrm{ml}$ of the same medium and transferred to T25 flask. Finally, the cells were cultured in a $37^{\circ} \mathrm{C}$ humidified air incubator with $5 \% \mathrm{CO}_{2}$. When there were sufficient cells, the latter were detached with trypsin and plated in another dish for further proliferation.

\section{Beauvericin cytotoxicity assessment}

The cell death rates of treated fibroblast were used as an indicator to assess the cytotoxicity of beauvericin. Cultured cells were transferred to 96 wells plate and treated with 12 different concentrations of beauvericin in triplicates $(0-50 \mu \mathrm{M})$ when they reached $50-60 \%$ confluence.

Cells were continuously exposed to the drugs for $48 \mathrm{~h}$ and subsequently assessed for cell death.

The viability of the cells was assessed based on their metabolic activity using the MTT proliferation assay, ${ }^{13}$ as follows: $24 \mathrm{~h}$ pre-treatment, fibroblast cells were starved in $100 \mu \mathrm{FBS}$ 
140 free media. After starvation, fibroblast cells were exposed to the drugs as described above. Four

141 hours prior to the end of the treatment, 10 $\mu 1$ MTT dye (100 mg Thiazolyl Blue Tetrazolium

142 Bromide, Sigma Aldrich, $20 \mathrm{ml} \mathrm{PBS}$ ) were added to the wells. In addition, $100 \mu \mathrm{MTT}$ stop 143 solution $(12 \mathrm{mM} \mathrm{HCl}, 0.05 \%$ isobutanol, $10 \% \mathrm{SDS})$ was added to cells before incubation at $37^{\circ} \mathrm{C}$

144 overnight. After 24h, the absorbance was measured at $550 \mathrm{~nm}$ on an ELISA plate reader. All

145 tests were carried out in triplicates of three biological replicates.

146

147

148

149

150

\section{Statistical analyses}

Efficacy data of all treatments against S. scabiei were analyzed by Kaplan Meier survival curves using software Statistical Package for the Social Sciences (SPSS, version 25). ${ }^{14}$ The statistical differences between data obtained with each treatment and the control for each experiment were measured by Log-rank test expressed by Chi- 2 results and P-values (degree of freedom $(\mathrm{df})=1$ ). P-value of $\leq 0.05$ was considered significant. The lethal concentration $\left(\mathrm{LC}_{50}\right)$ and lethal time $\left(\mathrm{LT}_{50}\right)$ necessary to kill half of the mite's population in addition to the lethal concentration $\left(\mathrm{LC}_{50}\right)$ necessary to kill hald of fibroblast cells and their standard error were calculated using the probit regression analysis in (SPSS). The median time of 50\% hatching $\left(\mathrm{HT}_{50}\right)$ of the eggs was assessed.

$\mathrm{LC}_{50}$ of all treatments were analyzed by the statistical comparison test of means (ANOVA) using SPSS. The Tukey test was used at the 5\% threshold for the separation of means.

\section{Results}

The three molecules, beauvericin, dimpylate, and ivermectin were highly efficient against motile stages of S. scabiei mites (Table 1 and Figure 1). The mortality rates in the control group were below 5\% during the first $8 \mathrm{~h}$ post-exposure. The survival and hatching curves of mites and eggs exposed to different drugs are presented in Figure 1. In all tests, significant differences were found between each molecule and the control except for the tests against S. scabiei eggs with 0.5 
$164 \mu \mathrm{M}$ of dimpylate and ivermectin. The highest mortality rates of all developmental stages were recorded with a concentration of $50 \mu \mathrm{M}$ of all drugs. The efficiency of each treatment decreased steadily with the decrease in the concentration of the molecules: the lowest mortality rates were recorded within the plates supplemented with $0.5 \mu \mathrm{M}$ of all drugs. Overall, a differential effect between the molecules and the concentration being used was notable $1 \mathrm{~h}$ post-exposure (Table 1).

The efficacy of the molecules at different concentrations can be put into the following order based on their chi-square value: beauvericin > ivermectin > dimpylate and ivermectin > 171 dimpylate > beauvericin against females and immature forms, respectively (Table 1). The 172 survival capacity seemed to be different according to the developmental stage of the mites.

173 Dimpylate and ivermectin had higher efficacy on S. scabiei immature motile stages when 174 compared to females; whereas, beauvericin displayed a higher efficacy on females at all 175 concentrations (Table 1).

176 The activity of all three molecules against S. scabiei eggs was evaluated for 5 days. Results 177 obtained with beauvericin, dimpylate or ivermectin were significantly different from those in the 178 control group (Table 1). Among all the molecules tested against the eggs of S. scabiei, 179 beauvericin demonstrated the best inhibition of hatching effect, when testing a concentration of $50 \mu \mathrm{M}$. The second-highest activity was recorded when treating eggs with the same concentration of dimpylate. The lowest activity was recorded at a concentration of $0.5 \mu \mathrm{M}$ of 182 dimpylate or ivermectin with no significant statistical difference compared to the negative 183 control (Table 1).

$184 \mathrm{LT}_{50}$ values were different between treatment groups against the motile stages of S. scabiei 185 (Table 1). The highest $\mathrm{LT}_{50}$ values (5.6 and 4.7h) were observed with a concentration of $0.5 \mu \mathrm{M}$ 186 of beauvericin and dimpylate against females and nymphs/larvae, respectively. The lowest $\mathrm{LT}_{50}$ 187 values $(1.1$ and $1 \mathrm{~h})$ were observed with a concentration of $50 \mu \mathrm{M}$ of dimpylate and ivermectin 
against females and nymphs/larvae, respectively. The median time for hatching of $50 \%$ of the eggs was also recorded in this study (Table 1).

190 A significant difference was recorded between $\mathrm{LC}_{50}$ values of the drugs at $1 \mathrm{~h}(\mathrm{~F}=68.779, \mathrm{df}=2$, 191 $\mathrm{P}<0.05), 2 \mathrm{~h}(\mathrm{~F}=12.809, \mathrm{df}=2, \mathrm{P}<0.05), 4 \mathrm{~h}(\mathrm{~F}=145.902, \mathrm{df}=2, \mathrm{P}<0.05), 5 \mathrm{~h}(\mathrm{~F}=59.758, \mathrm{df}$

$192=2, \mathrm{P}<0.05)$, and 6h- post exposure against females $(\mathrm{F}=12.809$, $\mathrm{df}=2, \mathrm{P}<0.05)$. The effect of 193 the drugs was not notable $3 \mathrm{~h}$ post exposure against females $(\mathrm{F}=0.39$, df $=2, \mathrm{P}>0.05)$. A 194 significant difference was also notable between $\mathrm{LC}_{50}$ values of molecules at any given time of 195 the test against larvae: $1 \mathrm{~h}(\mathrm{~F}=367.273, \mathrm{df}=2, \mathrm{P}<0.05), 2 \mathrm{~h}(\mathrm{~F}=1423.942, \mathrm{df}=2, \mathrm{P}<0.05), 3 \mathrm{~h}$ 196 $(\mathrm{F}=108.356, \mathrm{df}=2, \mathrm{P}<0.05), 4 \mathrm{~h}(\mathrm{~F}=86.263, \mathrm{df}=2, \mathrm{P}<0.05), 5 \mathrm{~h}(\mathrm{~F}=94.776, \mathrm{df}=2, \mathrm{P}<0.05)$, 197 and 6 h post exposure $(\mathrm{F}=68.387$, $\mathrm{df}=2, \mathrm{P}<0.05)$. Median times of $50 \%$ hatching of the eggs 198 are presented in Table 1. The highest median time for hatching (2.9 days) was recorded with a 199 concentration of $50 \mu \mathrm{M}$ of beauvericin. A significant difference was recorded between $\mathrm{LC}_{50}$ 200 values of the molecules against eggs at 5 days post-exposure $(\mathrm{F}=42.709, \mathrm{df}=2, \mathrm{P}<0.05)$.

201 The cytotoxic effect of beauvericin was assessed at $48 \mathrm{~h}$ post-exposure. The mycotoxin caused a 202 dose dependent reduction in cell viability and lethal concentration 50 was calculated. The human fibroblast cells were moderately sensitive to beauvericin toxicity and $\mathrm{LC}_{50}$ was $4.8 \mu \mathrm{M}$. 


\section{Discussion}

205 The mortality rate in the control groups was low $(<5 \%)$ during the first $8 \mathrm{~h}$ of the test indicating

206 suitable conditions of the bio-assays. The survival of S. scabiei outside its host is considered to

207 be the first limitation of in vivo studies. After 24h, the "natural" mortality rate at room

208 temperature reached $19 \%$ which indicates that mortalities recorded at $24 \mathrm{~h}$ may not be caused

209 only by the acaricide effect of the tested molecules; therefore, results recorded at $24 \mathrm{~h}$ post

210 inoculation are discarded.

211 The efficacies of macrocyclic lactones (including ivermectin) or organophosphates (like

212 dimpylate) against S. scabiei have been previously evaluated. ${ }^{12,15,19,22}$ However, most studies

213 evaluated the efficacy of such molecules against motile stages of $S$. scabiei with no

214 differentiation of the life stage. Studies evaluating the efficacy of acaricides against specific life

215 stages of S. scabiei are few. The present study demonstrated that the application of dimpylate

216 and ivermectin caused higher survival rates among females compared to immature forms. These

217 results are in accordance with those from Mounsey ${ }^{17}$ who observed that S. scabiei nymphs and

218 larvae were more vulnerable than females to ivermectin and moxidectin. Generally, larvae are

219 more sensitive due to their greater surface area/volume ratio meaning more drug is absorbed

220 through the cuticle during in vitro exposure. On the contrary, in the present study, S. scabiei

221 females seemed to be more vulnerable to beauvericin than immature forms. These results are in

222 accordance with those from Fu-Xing et al., 2002 reporting a higher induction of two kinds of

223 insecticides metabolic detoxifying enzymes by larvae of Musca domestica when compared to

224 adults.

225 The resistance of $S$. scabiei to commercial products exists and might increase in the future;

226 whereas, treatment failures of scabies infections in animals and humans have been previously

227 reported. ${ }^{20-23}$ Beauvericin is known to be an ionophoric cyclodepsipeptide which forms 
228 complexes with cations and increases the permeability of biological membranes. ${ }^{24-26}$ Given the

229 non-similarity of its mode of action to that of the commonly used neuro inhibitors, a cross-

230 resistance of $S$. scabiei mites against beauvericin is unlikely to happen.

231 The three drugs selected for the bioassays had a low $\mathrm{LT}_{50}$ value, indicating a rapid effect on the 232 mites. For beauvericin and dimpylate, $\mathrm{LT}_{50}$ values were related to the concentration of the 233 molecules (death occurred more rapidly among mites treated with higher concentrations).

234 The dose-response test recorded low $\mathrm{LC}_{50}$ values indicating high efficacy of all drugs at killing $S$.

235 scabiei mites. Moreover, $\mathrm{LC}_{50}$ values obtained in the present study were low when compared to 236 those obtained by Mounsey. ${ }^{17}$ The latter study reported that $50.5 \mu \mathrm{M}$ of ivermectin is required to 237 kill $50 \%$ of $S$. scabiei mites 1 h post-exposure (versus $45.1 \mu \mathrm{M}$ in our study). This result could be explained by the fact that the strain of S. scabiei and/or the assay conditions used in the present study were different.

240 The next generation of scabicide molecules needs to target $S$. scabiei eggs and ensuing 241 developmental stages. In the present study, high hatching rates were recorded among the eggs in 242 contact with dimpylate and ivermectin. These results are in accordance with Dourmishev ${ }^{27}$, Usha 243 and Nair ${ }^{28}$ demonstrating that presently used acaricides have a very limited inhibition of hatching 244 activity. The present study demonstrated that beauvericin was moderately active against the eggs 245 of S. scabiei.

246 Data about beauvericin cytotoxicity, especially against skin cell line are lacking. This lack of 247 data could explain why there are no maximum guidance levels. The present study assessed for 248 the first time the cytotoxic activity of beauvericin against primary fibroblast human skin cells. 249 Heilos et al. $^{30}$ investigated the cytotoxic activity of beauvericin against the principal constituent 250 of the epidermis, HEK2 keratinocyte $\left(\mathrm{IC}_{50}=5.4 \mu \mathrm{M}\right)$. Furthermore, systemic kinetics and effect 251 of beauvericin should also be assessed since the cyclic depsipeptide is transdermally absorbed ${ }^{31}$. 
252 The impact of beauvericin was also assessed against several nucleated human cells (IC50s

253 included human intestinal cell line Caco $2=3.9 \mu \mathrm{M}$; human liver cell line HEPG2 liver= 3.4 $\mu \mathrm{M}$;

254 human normal vascular endothelial cells HUVEC $=2.4 \mu \mathrm{M})^{30}$. The latter reviews revealed

255 cytotoxic activity against human cell lines at relatively low concentrations; nevertheless, the

256 present study demonstrated that the therapeutic index of beauvericin for scabies infection could

257 be high. The susceptible dose against motile stages of S. scabiei are extremely low when

258 compared that of all human cell lines. Furthermore, a study conducted by Taevernier et al. ${ }^{31}$

259 demonstrated that beauvericin concentration was 21 times higher in the epidermis than in the

260 dermis after topical application of the mycotoxin. Moreover, transdermal kinetics is mediated by

261 the outermost layer of the skin providing a protective reservoir for cyclic depsipeptides. ${ }^{31}$

262 In conclusion, this study presented the first evidence of in vitro efficacy of the mycotoxin

263 beauvericin against different developmental stages of S. scabiei mites. Beauvericin showed

264 higher efficacy against females and eggs of S. scabiei when compared to the two commercially

265 available acaricides, dimpylate, and ivermectin. Furthermore, beauvericin had low cytotoxicity

266 against fibroblasts. These preliminary results indicated that beauvericin may be considered as a

267 new scabicide molecule. Further studies assessing the possibility of beauvericin application to

268 treat scabies in humans or sarcoptic mange in animals are required. Bioavailability, toxicokinetic

269 properties, distribution, absorption, metabolization and excretion of the mycotoxin need now to

270 be documented. Studies measuring and confirming that the maximum concentration of

271 beauvericin in the skin of patients are within the in vitro susceptibility range are crucial. 


\section{Acknowledgment}

274 We are grateful to Radia Guechi, and Francis Moreau for their laboratory assistance

275 Funding:

276 This work was funded by the Lebanese National Council for Scientific Research (CNRS), grant

277 name (CNRS-L/USEK) and "Coopération pour l'évaluation et le développement de la recherche"

278 CEDRE grant number 37349SA.

279 Transparency declarations (conflicts of interest)

280 None to declare 


\section{REFERENCES}

282 1. Walton SF, Currie BJ. Problems in diagnosing scabies, a global disease in human and animal 283 populations. Clin Microbiol Rev. 2007; 20: 268-79.

284 2. Karimkhani C, Colombara DV, Drucker AM et al. The global burden of scabies: A cross285 sectional analysis from the global burden of disease study 2015. Lancet Infect

286 Dis. 2017; 17: 1247-54.

287 3. Engelman D, Cantey PT, Marks M et al. The public health control of scabies: Priorities for $288 \quad$ research and action. The Lancet. 2019; 394: 81-92

289 4. Lynar S, Currie BJ, Baird R. Scabies and mortality. Lancet Infect Dis. 2017; 17: 1234.

290 5. McCarthy JS, Kemp DJ, Walton SF et al. Scabies: More than just an irritation. Postgrad Med 291 J. 2004; 80: 382-7

292

6. Walton SF, Myerscough MR, Currie BJ. Studies in vitro on the relative efficacy of current acaricides for Sarcoptes scabiei var. hominis. Trans R Soc Trop Med Hyg. 2000; 94: 92-6.

294 7. Wang Q, Xu L. Beauvericin, a bioactive compound produced by fungi: A short 295 review. Molecules. 2012; 17: 2367-77.

8. Vega FE, Meyling NV, Luangsa-ard JJ et al. Fungal entomopathogens. Insect Pathol. 2012; 2: 171-220.

9. Mallebrera B, Prosperini A, Font $\mathrm{G}$ et al. In vitro mechanisms of beauvericin toxicity: $A$ review. Food Chem Toxicol. 2018; 111: 537-45. animal scabies. PLoS Negl Trop Dis. 2010; 4: e756. 
302 11. Brimer L, Henriksen SA, Gyrd-Hansen $\mathrm{N}$ et al. Evaluation of an in vitro method for acaricidal

303 effect. activity of parathion, phosmet and phoxim against Sarcoptes scabiei. Vet

$304 \quad$ Parasitol. 1993; 51: 123-35.

305 12. Brimer L, Bønløkke L, Pontoppidan C et al. A method for in vitro determination of the 306 acaricidal effect of ivermectin using Sarcoptes scabiei var. suis as test organism. Vet

$307 \quad$ Parasitol. 1995; 59: 249-55.

308

13. Mosmann T. Rapid colorimetric assay for cellular growth and survival: Application to proliferation and cytotoxicity assays. J Immunol Methods. 1983; 65: 55-63.

14. IBM Corp. Released 2017. IBM SPSS Statistics for Windows, Version 25.0. Armonk, NY: IBM Corp.

15. Huffam SE, Currie BJ. Ivermectin for Sarcoptes scabiei hyperinfestation. Int J Infect Dis. 1998; 2: 152-4.

16. Glaziou P, Cartel JL, Alzieu P et al. Comparison of ivermectin and benzyl benzoate for treatment of scabies. Trop Med Parasitol. 1993; 44: 331-2.

17. Mounsey KE, Walton SF, Innes A et al. In vitro efficacy of moxidectin versus ivermectin against Sarcoptes scabiei. Antimicrob Agents Chemother. 2017; 61: 381.

18. Baishya SK, Das A, Bardoloi RK. Therapaeutic efficacy of dormectin, diazinon and deltamethrin against mange mite infestation in pig. Indian J Hill Farming (India). 2003; 16: $82-5$

19. Feyera T, Admasu $P$, Abdilahi $Z$ et al. Epidemiological and therapeutic studies of camel mange in Fafan zone, eastern Ethiopia. Parasite Vector. 2015; 8: 612. 
323 20. Aussy A, Houivet E, Hébert V et al. Risk factors for treatment failure in scabies: A cohort study. Br J Dermatol. 2019; 180: 888-93.

325 21. Mounsey KE, Holt DC, McCarthy JS et al. Longitudinal evidence of increasing in vitro

326 tolerance of scabies mites to ivermectin in scabies-endemic communities. Arch

327 Dermatol. 2009; 145: 840-1.

328 22. Currie BJ, Harumal $\mathrm{P}$, McKinnon $\mathrm{M}$ et al. First documentation of in vivo and in vitro

329 ivermectin resistance in Sarcoptes scabiei. Clin Infect Dis. 2004; 39: e-e12.

330

23. Terada Y, Murayama N, Ikemura H et al. Sarcoptes scabiei var. canis refractory to ivermectin treatment in two dogs. Vet Dermatol. 2010; 21: 608-12.

24. Toman P, Makrlík E, Van̆ura P. On the complexation of the sodium cation with beauvericin: Experimental and theoretical study. Monatsh Chem. 2011; 142: 779-82.

25. Wätjen W, Debbab A, Hohlfeld A et al. The mycotoxin beauvericin induces apoptotic cell death in H4IIE hepatoma cells accompanied by an inhibition of NF- $\mathrm{BB}$-activity and modulation of MAP-kinases. Toxicol Lett. 2014; 231: 9-16.

26. Lu C, Lin H, Chen B et al. Beauvericin-induced cell apoptosis through the mitogen-activated protein kinase pathway in human nonsmall cell lung cancer A549 cells. J Toxicol

$$
\text { Sci. 2016; 41: 429-37. }
$$

27. Dourmishev AL, Dourmishev LA, Schwartz RA. Ivermectin: Pharmacology and application in dermatology. Int J Dermatol. 2005; 44: 981-8.

28. Usha V, Nair TG. A comparative study of oral ivermectin and topical permethrin cream in the treatment of scabies. J Am Acad Dermatol. 2000; 42: 236-40. 
344 29. Jestoi M. Emerging fusarium-mycotoxins fusaproliferin, beauvericin, enniatins, and

345 moniliformin-A review. Crit Rev Food Sci Nutr. 2008; 48: 21-49.

346 30. Heilos D, Rodríguez-Carrasco Y, Englinger B et al. The natural fungal metabolite beauvericin 347 exerts anticancer activity in vivo: A pre-clinical pilot study. Toxins. 2017; 9: 258.

348 31. Taevernier L, Veryser L, Roche N, Peremans K, Burvenich C, Delesalle C, De Spiegeleer B.

349 Human skin permeation of emerging mycotoxins (beauvericin and enniatins). J. Expo. Sci.

$350 \quad$ Environ. Epidemiol. 2016; 26, 277-287.

351 


\section{$353 \quad$ Legend of figure}

354 Figure 1: Curves representing survival (of motile stages) and hatching (of eggs) of S. scabiei

355 exposed to acaricide molecules at different concentrations: a) $0.5 \mu \mathrm{M}$, b) $5 \mu \mathrm{M}$, and c) $50 \mu \mathrm{M}$.

356 For each treatment, observed survivals and hatchings are presented using curves with markers;

357 filled circle: beauvericin; filled square: dimpylate; filled triangle: ivermectin; open circle: control

358 
1

2

3

4

\begin{tabular}{|c|c|c|c|c|c|c|c|c|c|c|}
\hline \multirow{2}{*}{\multicolumn{2}{|c|}{$\begin{array}{l}\text { Drugs and } \\
\text { concentrations }\end{array}$}} & \multicolumn{3}{|c|}{ Females } & \multicolumn{3}{|c|}{ Nymphs \& larvae } & \multicolumn{3}{|c|}{ Eggs } \\
\hline & & \multirow{2}{*}{$\begin{array}{c}X^{2} \\
112\end{array}$} & \multirow{2}{*}{$\begin{array}{c}\boldsymbol{P} \\
<0.05\end{array}$} & \multirow{2}{*}{$\begin{array}{c}\mathbf{L T}_{\mathbf{5 0}} \pm \text { S.E. } \\
\text { (h) }\end{array}$} & \multirow{2}{*}{$\begin{array}{c}X^{2} \\
34.4\end{array}$} & \multirow{2}{*}{$\begin{array}{c}P \\
<0.05\end{array}$} & \multirow{2}{*}{$\begin{array}{c}\mathbf{L T}_{\mathbf{5 0}} \pm \text { S.E. } \\
\text { (h) }\end{array}$} & \multirow{2}{*}{$\begin{array}{l}X^{2} \\
39 \\
\end{array}$} & \multirow{2}{*}{$\begin{array}{c}P \\
<0.05\end{array}$} & \multirow{2}{*}{$\begin{array}{c}\mathrm{HT}_{50} \pm \text { S.E. } \\
\text { (h) }\end{array}$} \\
\hline$\cong$ & $0.5 \mu \mathrm{M}$ & & & & & & & & & \\
\hline 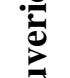 & $5 \mu \mathrm{M}$ & 159.7 & $<0.05$ & $1.9 \pm 0$ & 79 & $<0.05$ & $4.1 \pm 0.2$ & 54.2 & $<0.05$ & $2.5 \pm 0.1$ \\
\hline$\underset{\mathscr{D}}{\mathbb{0}}$ & $50 \mu \mathrm{M}$ & 165.9 & $<0.05$ & $1.4 \pm 0$ & 124 & $<0.05$ & $2.3 \pm 0.1$ & 85.9 & $<0.05$ & $2.9 \pm 0.1$ \\
\hline \multirow{3}{*}{ 营 } & $0.5 \mu \mathrm{M}$ & 5.9 & $<0.05$ & $5.6 \pm 0.17$ & 39.7 & $<0.05$ & $4.5 \pm 0.2$ & 1.3 & $>0.05$ & $1.5 \pm 0$ \\
\hline & $5 \mu \mathrm{M}$ & 154.3 & $<0.05$ & $3.2 \pm 0.1$ & 172 & $<0.05$ & $2 \pm 0.1$ & 12.1 & $<0.05$ & $1.8 \pm 0$ \\
\hline & $50 \mu \mathrm{M}$ & 167 & $<0.05$ & $1.1 \pm 0$ & 167.3 & $<0.05$ & $1.1 \pm 0$ & 38.8 & $<0.05$ & $2.3 \pm 0.1$ \\
\hline \multirow{3}{*}{ 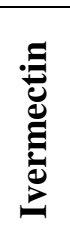 } & $0.5 \mu \mathrm{M}$ & 151.4 & $<0.05$ & $2.8 \pm 0.1$ & 166.5 & $<0.05$ & $1.6 \pm 0$ & 0.3 & $>0.05$ & $1.4 \pm 0$ \\
\hline & $5 \mu \mathrm{M}$ & 156.8 & $<0.05$ & $2.4 \pm 0.1$ & 166.9 & $<0.05$ & $1.2 \pm 0$ & 6.5 & $<0.05$ & $1.6 \pm 0$ \\
\hline & $50 \mu \mathrm{M}$ & 166.5 & $<0.05$ & $1.6 \pm 0.1$ & 164.3 & $<0.05$ & $1 \pm 0$ & 19.8 & $<0.05$ & $1.9 \pm 0.1$ \\
\hline
\end{tabular}

5

$6 \quad$ Note: $X^{2}$ : Chi-square value; $L T_{50}$ : Lethal Time to kill $50 \%$ of mites; S.E.: Standard error; $h$ :

$7 \quad$ Hour; P: probability value; $\mu$ M: micromolar. 
2 Table 2: Concentrations of different molecules required to kill $50 \%$ of $S$. scabiei mites (females,

3 nymphs/larvae and eggs).

\begin{tabular}{|c|c|c|c|c|c|c|c|c|c|c|c|c|c|c|c|c|c|}
\hline & \multicolumn{17}{|c|}{$\mathrm{LC}_{50}(\mu \mathrm{M}) \pm$ S.E. } \\
\hline \multirow[b]{2}{*}{ 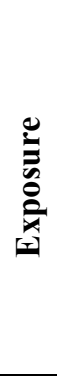 } & \multicolumn{2}{|c|}{$1 \mathrm{~h}$} & \multicolumn{2}{|c|}{$2 \mathrm{~h}$} & \multicolumn{2}{|c|}{$3 \mathrm{~h}$} & \multicolumn{2}{|c|}{$4 h$} & \multicolumn{2}{|c|}{$5 \mathrm{~h}$} & \multicolumn{2}{|c|}{$6 \mathrm{~h}$} & \multicolumn{2}{|c|}{$7 \mathrm{~h}$} & \multicolumn{2}{|c|}{$8 \mathrm{~h}$} & \multirow[t]{2}{*}{$n \sum_{\pi}^{\infty}$} \\
\hline & 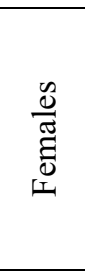 & 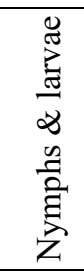 & 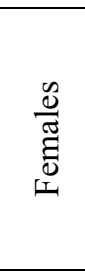 & 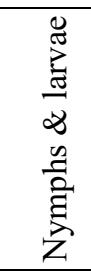 & 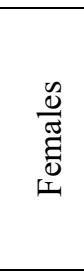 & 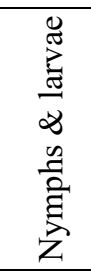 & 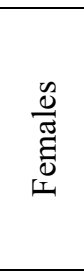 & 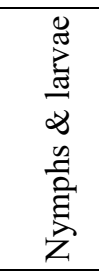 & 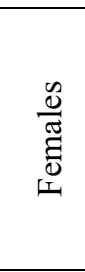 & 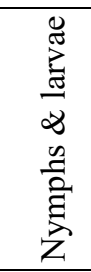 & 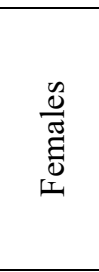 & 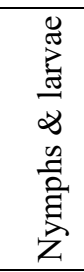 & 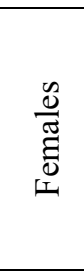 & 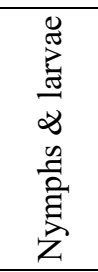 & 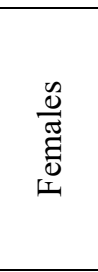 & 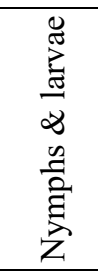 & \\
\hline 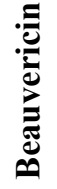 & $\begin{array}{c}34.7 \pm \\
3.9^{\mathrm{c}}\end{array}$ & $\begin{array}{c}48.1 \\
\pm 1.7^{\mathrm{b}}\end{array}$ & $\begin{array}{c}7.8 \pm \\
5.1^{\mathrm{a}}\end{array}$ & $\begin{array}{c}39.5 \pm \\
3^{\mathrm{b}}\end{array}$ & $\underset{\mathrm{a}}{2 \pm 0.9}$ & $\begin{array}{c}28.4 \pm \\
2.6^{\mathrm{b}}\end{array}$ & $\begin{array}{c}0.7 \pm 0 \\
.2^{\mathrm{b}}\end{array}$ & $\begin{array}{c}18.9 \pm \\
1.9^{\mathrm{b}}\end{array}$ & $\underset{\mathrm{b}}{0.3 \pm 0}$ & $\begin{array}{c}13.7 \pm \\
1.3^{\mathrm{b}}\end{array}$ & $\underset{\mathrm{b}}{0.3 \pm 0}$ & $\begin{array}{c}10.4 \pm \\
1.2^{\mathrm{b}}\end{array}$ & $\underset{\mathrm{a}}{0.3 \pm 0}$ & $\begin{array}{c}1.7 \pm 0 . \\
6^{\mathrm{b}}\end{array}$ & $0.3 \pm 0^{\mathrm{a}}$ & $0.9 \pm 0^{\mathrm{a}}$ & $\begin{array}{c}77.5 \\
\pm 1.8^{\mathrm{a}}\end{array}$ \\
\hline 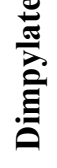 & $\begin{array}{c}7.09 \pm \\
0^{\mathrm{a}}\end{array}$ & $\begin{array}{c}6.9 \pm \\
1^{\mathrm{a}}\end{array}$ & $\begin{array}{l}5.9 \pm \\
0.2^{\mathrm{a}}\end{array}$ & $\begin{array}{c}3.3 \pm 0 \\
.2^{\mathrm{a}}\end{array}$ & $\begin{array}{c}4.1 \pm 0 \\
.1^{\mathrm{a}}\end{array}$ & $\begin{array}{c}2.3 \pm 0 \\
.7^{\mathrm{a}}\end{array}$ & $\begin{array}{c}3.9 \pm 0 \\
.1^{\mathrm{a}}\end{array}$ & $\underset{\mathrm{a}}{1.7 \pm 0}$ & $\begin{array}{c}2.5 \pm 0 \\
.2^{\mathrm{a}}\end{array}$ & $\underset{\mathrm{a}}{0.5 \pm 0}$ & $\begin{array}{c}1.5 \pm 0 \\
.1^{\mathrm{a}}\end{array}$ & $\underset{\mathrm{a}}{0.5 \pm 0}$ & $\begin{array}{c}1.1 \pm 0 \\
.4^{\mathrm{a}}\end{array}$ & $\underset{\mathrm{a}}{0.4 \pm 0}$ & $\begin{array}{c}0.8 \pm 0 . \\
1^{\mathrm{b}}\end{array}$ & $0.4 \pm 0^{\mathrm{a}}$ & $\begin{array}{c}77.5 \\
\pm 1.8^{\mathrm{a}}\end{array}$ \\
\hline 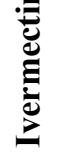 & $\begin{array}{c}45.1 \pm \\
0.9^{\mathrm{b}}\end{array}$ & $\begin{array}{l}5.7 \pm \\
0.8^{\mathrm{a}}\end{array}$ & $\begin{array}{c}26 \pm 1 \\
.5^{\mathrm{b}}\end{array}$ & $\begin{array}{c}0.4 \pm 0 \\
\mathrm{a}\end{array}$ & $\begin{array}{c}4.7 \pm 3 \\
.9^{\mathrm{a}}\end{array}$ & $\underset{\mathrm{a}}{0.3 \pm 0}$ & $\begin{array}{c}0.3 \pm 0 \\
\mathrm{~b}\end{array}$ & $\underset{\mathrm{a}}{0.3 \pm 0}$ & $\underset{\mathrm{b}}{0.3 \pm 0}$ & $\underset{\mathrm{a}}{0.3 \pm 0}$ & $\underset{\mathrm{b}}{0.3 \pm 0}$ & $\underset{\mathrm{a}}{0.3 \pm 0}$ & $\underset{\mathrm{a}}{0.3 \pm 0}$ & $\underset{\mathrm{a}}{0.3 \pm 0}$ & $0.3 \pm 0^{\mathrm{a}}$ & $0.3 \pm 0^{\mathrm{a}}$ & $\begin{array}{l}202.6 \\
\pm 16.5^{\mathrm{b}}\end{array}$ \\
\hline
\end{tabular}

4

5 Note: LC $50:$ Lethal Concentration to kill 50\% of mites; S.E.: Standard error; $h$ : Hour; $\mu$ M:

6 micromolar

$7 \quad$ *Values followed by the same letter in the same column are not significantly different at

8 the 5\% threshold 
bioRxiv preprint doi: https://doi.org/10.1101/814707; this version posted October 23,2019 . The copyright holder for this preprint (which was not

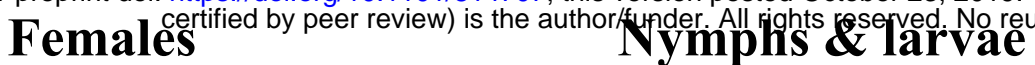
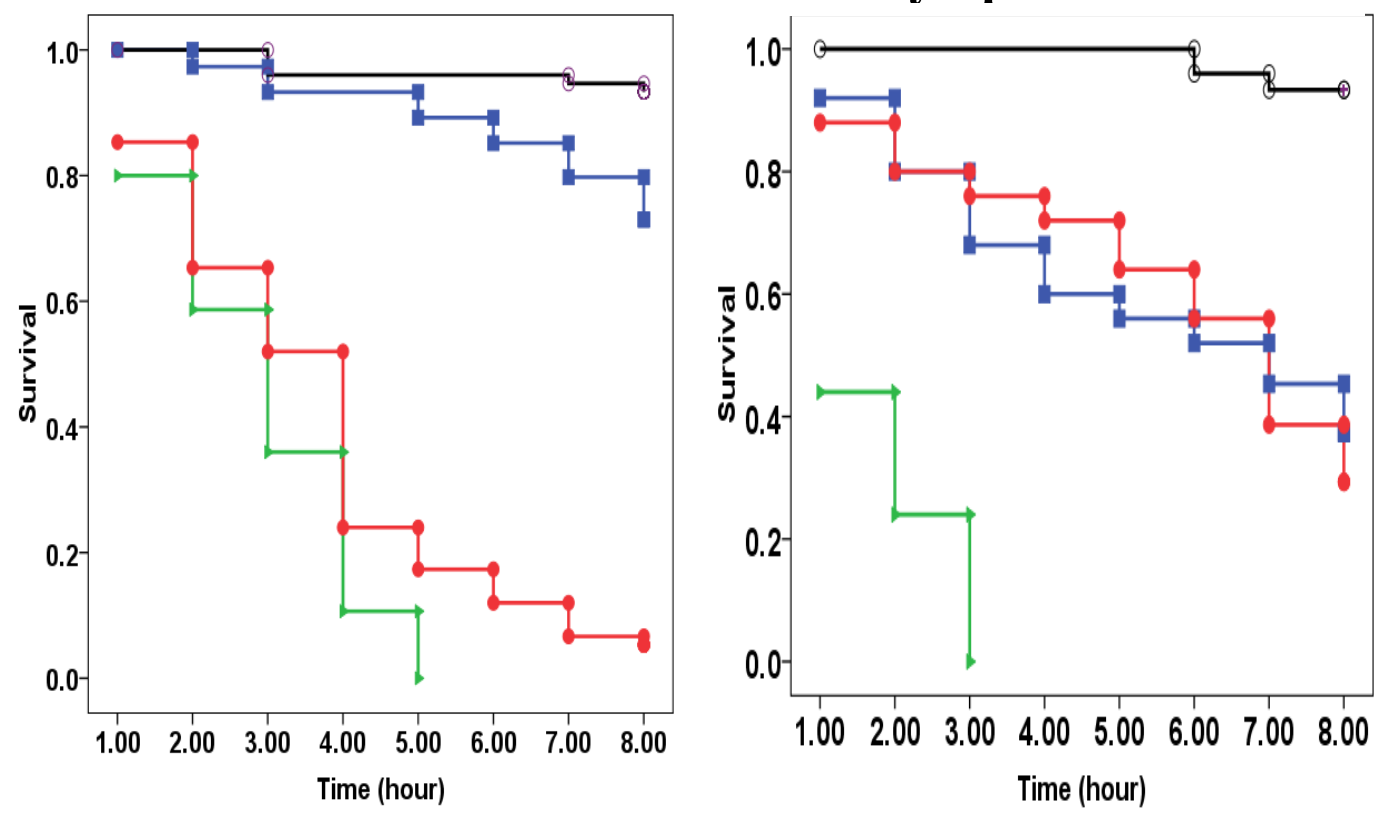

Eggs
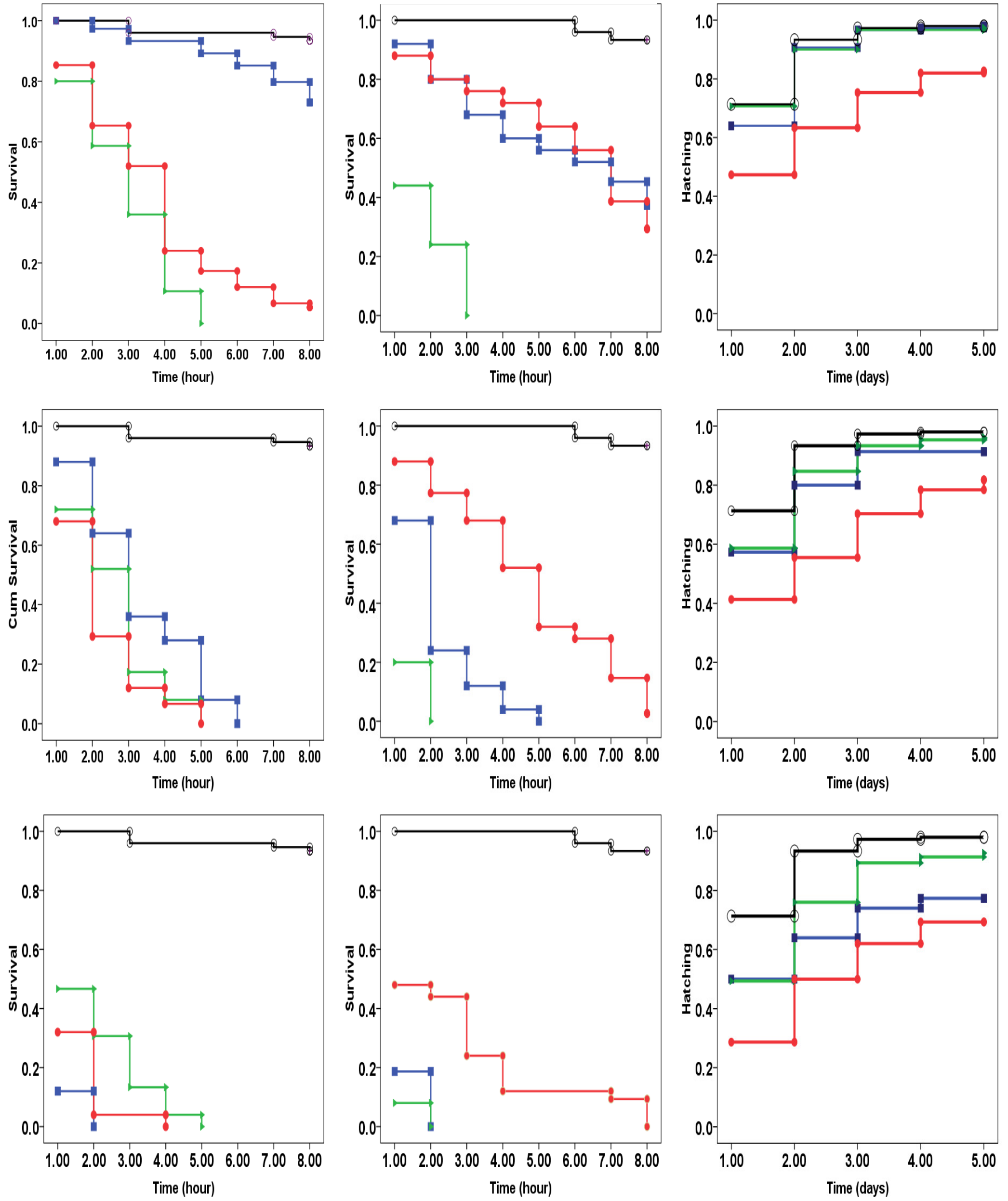